Onomástica Desde América Latina, n.4, v.2, julho - dezembro, 2021, p.130-146.ISSN 2675-2719

https://doi.org/10.48075/odal.v0i0.27524

\title{
LEXICO E ONIONÍMIA: um estudo de nomes próprios de cachaças da cidade de Salinas-MG ${ }^{1}$
}

\section{LEXICON AND ONONYMY: a study of proper names of cachaças in the city of Salinas-MG}

\author{
Mauricio Alves de Souza Pereira \\ Doutorando em Estudos Linguísticos \\ Universidade Federal de Minas Gerais \\ https://orcid.org/0000-0002-8691-8589 \\ mauricio.souza.pereira@educacao.mg.gov.br
}

\begin{abstract}
Resumo
Os estudos do léxico, isto é, das palavras que compõem uma língua, permitem-nos compreender o sistema de vida e as práticas culturais dos falantes. Nesse sentido, a Onomástica se relaciona com os estudos lexicais, visto que, ao estudar os nomes próprios - nomes de pessoas, de lugares, de produtos comerciais -, criados pelos seres humanos, é possível identificar motivações de ordem cultural. Dito isso, o objetivo deste trabalho é analisar, com as contribuições da Onionímia, o processo de nomeação de três cachaças produzidas na região de Salinas, Minas Gerais: Puluzinha, Primadela e Caladinha. Para isso, ancorar-nos-emos nas pesquisas acerca do léxico e da onomástica, como Guérios (1973) e Neumeier (2008).
\end{abstract}

Palavras-chave: léxico, Onomástica, onionímia, cachaça, Salinas.

\section{Abstract}

The study of the lexicon, the words that make up a language, allows us to understand the speakers' system of life and cultural practices. In this sense, onomastics is related to lexical studies, since, when studying proper names names of people, places, commercial products - created by human beings, it is possible to identify cultural motivations. That said, the objective of this work is to analyze, with the contributions of Onyonymy, the naming process of three cachaça produced in the region of Salinas, Minas Gerais: Puluzinha, Primadela and Caladinha. For this, we will anchor ourselves in researches about the lexicon and onomastics, such as Guérios (1973) and Neumeier (2008).

Keywords: lexicon, Onomastics, Onyonymy, cachaça; Salinas.

"Adorada ou demonizada, a cachaça está na raiz de nossa cultura e de nossas práticas sociais”.

Museu da cachaça de Salinas

\section{Introdução}

Muito embora façam parte do cotidiano e sejam familiares, as palavras que compõem o léxico de uma língua, quando analisadas com afinco, são capazes de evidenciar a história, a cultura, as ideologias e os valores do grupo de falantes que utilizam e manipulam determinada língua. Isso se estende aos nomes próprios, que, assim como os demais nomes que compõem

\footnotetext{
${ }^{1}$ Artigo produzido como requisito para a conclusão da disciplina Onomástica, ministrada pela Professora Marcia Sipavicius Seide, da Unioeste em 2021.
} 
Onomástica Desde América Latina, n.4, v.2, julho - dezembro, 2021, p.130-146.ISSN 2675-2719 https://doi.org/10.48075/odal.v0i0.27524

o léxico de uma língua, deixam transparecer fatores interessantes de serem observados e postos à luz de estudos e pesquisas.

Os estudos de nomes próprios remontam à Antiguidade e, cada vez mais, com o desenvolvimento dos estudos linguísticos, aumenta-se o interesse pelos aspectos que envolvem tais nomes, não somente aqueles de ordem linguística, mas, sobretudo, aqueles relacionados à história, à cultura e ao sistema de valores de um povo, fatores que motivam a escolha de muitos nomes.

A Onomástica é uma área de estudos interdisciplinar, que utiliza metodologias de estudo de outras áreas e, ao mesmo tempo, oferece dados importantes para a compreensão da História, da Geografia, da Antropologia, das Ciências Sociais, entre outros. Apesar de os estudos onomásticos enfatizarem a análise de nomes próprios de pessoas (antroponomástica) e de lugares (toponomástica), há outros nomes próprios que também têm ganhado visibilidade nesse campo de pesquisas, como é o caso do processo de nomeação de produtos comerciais, área conhecida como Onionímia.

O estudo dos oniônimos permite compreender quais fatores envolvem o processo de nomeação de elementos comerciais, não somente os linguísticos, mas também aqueles que envolvem a cultura e o sistema de valores do nomeador. Dito isso, é objetivo deste trabalho realizar apontamentos teóricos acerca de uma das subáreas da Onomástica: a Onionímia responsável pela análise de nomes próprios comerciais -, e analisar, dentro do léxico dos moradores de Salinas/MG, o processo de nomeação de três cachaças produzidas na região: Puluzinha, Primadela e Caladinha. São observados, na análise desses nomes, os fatores linguísticos e sociais envolvidos na nomeação das bebidas, com base em estudos lexicais e onomásticos e nos relatos de salinenses que falam sobre a história dessas cachaças.

\section{Estudos lexicais e onomásticos}


Onomástica Desde América Latina, n.4, v.2, julho - dezembro, 2021, p.130-146.ISSN 2675-2719 https://doi.org/10.48075/odal.v0i0.27524

A linguagem possui um forte caráter social, tendo em vista que é fruto da natureza humana. Por meio dela, os indivíduos expressam aquilo que sentem e pensam e, principalmente, estabelecem interação, fator essencial para a vida em sociedade. Nesse sentido, as palavras são as ferramentas pelas quais o homem exprime aquilo que deseja; é através delas que são nomeados os objetos, as pessoas, os produtos, os sentimentos e tudo aquilo que se conhece (PEREIRA, 2021).

Ao conjunto de palavras que nomeiam e compõem o acervo linguístico de uma população dá-se o nome de léxico, um conjunto dinâmico e heterogêneo de palavras que formatam o conhecimento internalizado e por meio do qual o falante se expressa. Para Coelho (2008), o léxico é “o inventário das unidades significativas responsáveis pela conceituação e representação do universo empírico natural e do sociocultural produzido pela atividade dos homens em sociedade" (COELHO, 2008:14).

Logo, por serem as palavras o espelho de todas as práticas sociais, as ciências do léxico tornam-se a área dos estudos da língua que melhor consegue refletir a relação do indivíduo com a sociedade e, portanto, com a cultura. O léxico evidencia, através das palavras das quais o falante lança mão, isto é, das suas escolhas lexicais, os pensamentos, os sentimentos, as ideologias, as crenças, os costumes e todas as suas peculiaridades. Consoante Sapir (1969),

o léxico da língua é que mais nitidamente reflete o ambiente físico e social dos falantes. O léxico completo de uma língua pode se considerar, na verdade, como o complexo inventário de todas as idéias, interesses e ocupações que açambarcam a atenção da comunidade (SAPIR, 1969: 45).

A afirmação de Sapir é sustentada e expandida por Biderman (1978), a qual afirma que

\footnotetext{
o léxico de qualquer língua constitui um vasto universo de limites imprecisos e indefinidos. Abrange todo o universo conceptual dessa língua. Qualquer sistema léxico é a somatória de toda experiência acumulada de uma sociedade e do acervo da sua cultura através das idades. Os membros dessa mesma sociedade funcionam como sujeitos-agentes no processo de perpetuação e reelaboração contínua do léxico de sua língua (BIDERMAN, 1978: 139).
} 
Onomástica Desde América Latina, n.4, v.2, julho - dezembro, 2021, p.130-146.ISSN 2675-2719 https://doi.org/10.48075/odal.v0i0.27524

Assim, não há dúvidas de que estudar o léxico de uma comunidade permite entender seu sistema de valores e crenças, bem como a sua cultura, o que se comprova com o posicionamento de Isquerdo (2001: 91), para quem o léxico, na medida em que recorta realidades do mundo, define, também, fatos da cultura.

A ciência do léxico responsável pelo estudo da palavra é a Lexicologia, que, entre outras funções, se atém à relação do léxico de uma língua com o universo natural, social e cultural, à abordagem da palavra e seu papel na construção de visões de mundo e à influência do contexto em cada palavra (BARBOSA, 1990).

Integrada à lexicologia está a Onomástica, que também se atém ao estudo das palavras, mas, especificamente, àquelas que designam os nomes próprios. Conforme salienta Seabra

A Onomástica se integra à lexicologia, caracterizando-se como a ciência da linguagem que possui duas áreas de estudo: a Antroponímia e a Toponímia - ambas se constituem de elementos lingüísticos que conservam antigos estágios denominativos (SEABRA, 2006: 1953).

De etimologia grega, cuja base é o vocábulo onoma - nome -, a Onomástica investiga todos os tipos de nomes próprios, desde os nomes de lugares, de pessoas, de animais de estimação, de marcas comerciais etc. Os nomes próprios fazem parte do mesmo arcabouço do qual fazem parte os outros vocábulos, porém apresentam particularidades em seu conteúdo. Para Amaral e Seide (2020),

Os nomes próprios são caracterizados por serem usados para fazer referência direta a um ser único sem indicar uma característica que seria própria do ser referenciado e, na língua escrita, devem ser grafados com letra inicial maiúscula (característica esta válida para a língua portuguesa, mas não para todos os idiomas) (AMARAL E SEIDE, 2020: 69).

Nos estudos dos nomes próprios, destacam-se a Antroponomástica, responsável pela investigação dos nomes de pessoas, e a Toponomástica, que analisa os nomes de lugares bairros, cidades, rios, montanhas etc. Mais recentemente, tem ganhado espaço a chamada Onionímia, que se preocupa com o processo de nomeação de produtos comerciais. A cada dia, no sistema capitalista em que vivemos, surgem novos e interessantes produtos, os quais são 
Onomástica Desde América Latina, n.4, v.2, julho - dezembro, 2021, p.130-146.ISSN 2675-2719 https://doi.org/10.48075/odal.v0i0.27524

nomeados seguindo, assim como os nomes de pessoas e de lugares, critérios específicos, sobretudo relacionados à cultura e às práticas sociais, conforme se discute na próxima seção.

\section{Estudos de nomes comerciais: onionímia}

O estudo dos oniônimos ganhou relevância a partir das pesquisas empreendidas pelo Professor Rosário Farâni Mansur Guérios. O nome, criado pelo pesquisador, advém de ónion ou ónia, que significa artigo comercial, acompanhado de ónyma, "nome", formando o vocábulo oniônimo (GUÉRIOS, 1973). Sob essa perspectiva, Guérios define onionímia como a disciplina que se ocupa dos estudos dos nomes próprios de artigos ou produtos das indústrias. Para o autor, pode-se também utilizar o termo "Onomástica Industrial” ou “Onionomástica".

Em seus estudos sobre os nomes comerciais, Guérios afirma que os oniônimos funcionam com uma característica adjetiva, tendo em vista que qualificam o produto que nomeiam de acordo com os seus atributos. Em suas considerações, o autor salienta que, apesar de se configurarem como inovações da língua, que levam em conta a criatividade do criador dos nomes, os oniônimos, assim como as outras palavras do léxico, são formadas a partir de uma base ou modelo, o que faz com que, nas palavras de Guérios, sejam uma espécie de "deformação de nomes comuns".

Com relação à análise desses nomes, o autor observa que podem ser levados em conta os aspectos gramaticais - como a ortografia e a prosódia - e estilísticos - como o modo pelo qual os nomes surgiram (motivações), o sentido que eles possuem etc.

No que se refere à ortografia, Guérios observa que, na criação de nomes comerciais, é muito comum o uso de letras pouco usuais na língua - no caso do português, o uso das letras $k, y$ e das combinações th e ph, por exemplo -, bem como a mistura de letras maiúsculas e minúsculas em uma mesma palavra (como Vick VapoRub, nome de uma pomada para congestão nasal). 
Onomástica Desde América Latina, n.4, v.2, julho - dezembro, 2021, p.130-146.ISSN 2675-2719 https://doi.org/10.48075/odal.v0i0.27524

Quanto às questões de ordem fonética, o autor menciona alguns processos comuns na criação de nomes próprios comerciais, a exemplo da síncope (supressão de sons no interior da palavra formada, como Lavolho - lava + olho) e a aférese (supressão de som inicial da palavra - como Mengo, nome de uma marca de cigarro derivada de Flamengo). Uma interessante observação feita por Guérios é que muitos nomes estrangeiros não conservam a pronúncia da língua da qual se originaram, a exemplo do nome Royal.

Quanto aos aspectos morfológicos dos nomes próprios, Guérios aponta as palavras formadas por derivação, a exemplo do nome Melhoral (melhor + al), e por composição, como o vocábulo Gasúnico (gás + único). O autor também cita a presença de barbarismos na formação desses itens, a exemplo da marca de calçado Pizar Firme, grafada com z.

De acordo com Guérios, muitos nomes comerciais são estrangeirismos, há palavras derivadas do latim, do grego, do espanhol e de diversas outras línguas, assim como hibridismos dessas línguas. A motivação para isso, segundo o autor, é que os nomes estrangeiros tendem a conferir mais prestígio ao produto e, por isso, ele passa a ser mais procurado e consumido pelo público consumidor.

Guérios menciona, ainda, que, devido à concorrência no mercado comercial, muitos produtos possuem nomes próximos ou muito parecidos, a exemplo das bolachas Marina, Maria e Marie. Sob esse mesmo ângulo, o autor observa que alguns nomes próprios passam a ser usados como nomes comuns, devido ao prestígio da marca e à sua considerável utilização no cotidiano da população. Há o exemplo de Gilete, que, devido ao prestígio que ganhou ao longo do tempo, é utilizado como nome comum. Tal exemplo é mais bem discutido por Amaral e Seide (2020):

É bem conhecida a história da marca Gillete, uma lâmina de barbear descartável que, após certo número de usos, é descartada, ao contrário da antiga navalha. Gillete é o sobrenome de King Camp Gillete (1855-1932), inventor da lâmina de barbear (GARCÍA-CASTAÑóN, 2001, p. 66). Esse sobrenome passou a ser marca da lâmina. No Brasil, o produto fez tanto sucesso, que se passou a chamar de gilete qualquer lâmina de barbear, mesmo que de outras marcas (AMARAL E SEIDE, 2020: 184). 
Onomástica Desde América Latina, n.4, v.2, julho - dezembro, 2021, p.130-146.ISSN 2675-2719 https://doi.org/10.48075/odal.v0i0.27524

Conforme Guérios, a motivação para a criação de um nome comercial pode ser diversa, tendo influência do nome da indústria que produz o artigo comercial, o nome do dono da marca, as características do produto, entre outros. No momento em que o nome é criado, vários fatores são levados em conta. De acordo com Neves (1971),

\begin{abstract}
Assim como o pai que batiza os seus filhos com os nomes que estão na moda, ou com aqueles que lhes interessam por qualquer motivo, principalmente por razões de ordem familiar ou afetiva, também o comerciante cria seus neologismos dentro desses critérios e de mais um outro, que escapa ao primeiro: o nome próprio deve ser eficaz, tanto no sentido de representar o objeto ou a casa que denomina, como no de “atuação social” junto ao público consumidor ou clientela (NEVES, 1971:30).
\end{abstract}

A atuação social do nome, conforme discutido por Neves, é muito importante na escolha do nome do artigo comercial. Tal observação é reforçada por Couto (2007), o qual afirma que a escolha do nome está relacionada ao contexto em que ele foi criado, relação que, segundo o autor, ocorre "entre língua e meio ambiente mental” (COUTO, 2007: 443).

Analisando os aspectos que devem ser levados em conta na criação dos nomes comerciais, Neumeier (2008) propõe que sejam observados sete critérios. O primeiro critério é a distinguibilidade, em que o nome comercial precisa se distinguir dos demais no sentido de se destacar perante os seus concorrentes e ter visibilidade para o público consumidor. $\mathrm{O}$ segundo critério é a brevidade, que se refere ao tamanho do nome comercial; para o autor, ele deve ser curto, no intuito de ser lembrado e usado com facilidade pelos consumidores. Em seguida, Neumeier comenta a necessidade da conveniência, em que o nome deve estar adequado ao objetivo comercial da empresa, e da grafia e pronúncias fáceis, de modo que o consumidor consiga ler e pronunciar corretamente o nome e não se sentir ignorante devido à complexidade do nome. Posteriormente, o autor cita a agradabilidade, em que o nome precisa ser agradável à audição, e a extensibilidade, para a qual o nome comercial precisa sugerir uma interpretação visual e possibilitar possibilidades criativas. Por fim, Neumeier aponta a possibilidade de proteção, haja vista que o nome precisa ser registrado e usado em amplitude. 
Onomástica Desde América Latina, n.4, v.2, julho - dezembro, 2021, p.130-146.ISSN 2675-2719 https://doi.org/10.48075/odal.v0i0.27524

Logo, o nome comercial leva em conta fatores não só relacionados à necessidade de atingir o público consumidor, mas também voltados às crenças e aos valores daquele que nomeia, podendo, inclusive, haver relação com a cultura. Essa relação cultural é observada na nomeação de cachaças na cidade mineira de Salinas, considerada como a Capital Nacional da Cachaça - conforme a discussão da próxima seção.

\section{A relação entre Salinas e a cachaça}

Situada no norte do estado de Minas Gerais, a cidade de Salinas, hoje, é uma referência na produção de cachaça, e isso levou à obtenção do título de Capital Nacional da Cachaça, por meio da Lei Ordinária nº 13.773/2018 (BRASIL, 2018).

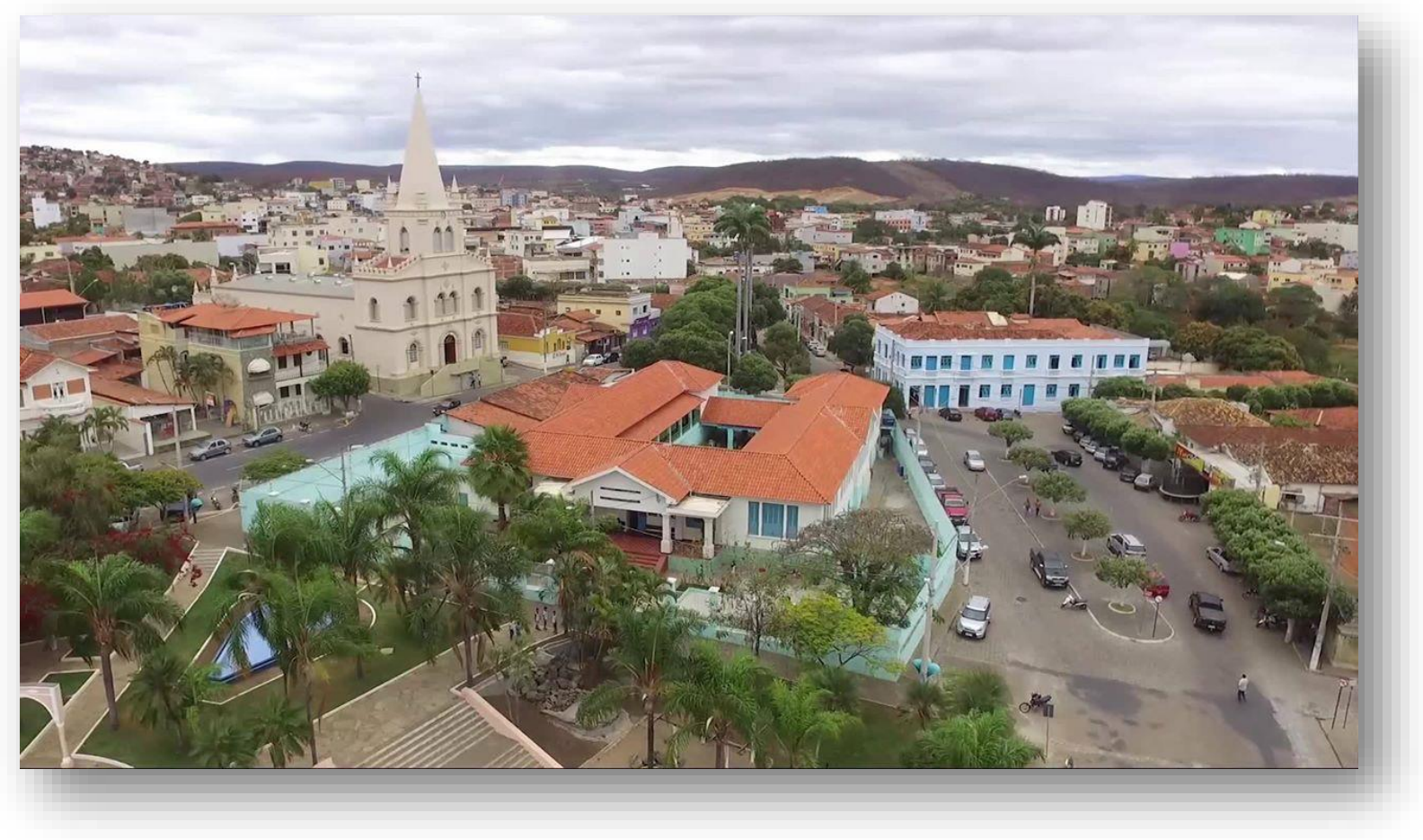

Foto 1 - Salinas-MG

Fonte: Prefeitura de Salinas

O histórico da cachaça, na cidade de Salinas, remonta ao Brasil Colônia e à vinda de grandes latifundiários, sobretudo da Bahia, para a região. Os fazendeiros realizavam a 
Onomástica Desde América Latina, n.4, v.2, julho - dezembro, 2021, p.130-146.ISSN 2675-2719 https://doi.org/10.48075/odal.v0i0.27524

produção de cachaça como uma atividade secundária - para a comercialização em pequenas quantidades e para o consumo próprio -, pois o motor da economia à época eram as atividades agropecuárias. Com o passar do tempo e a dedicação dos produtores salinenses em produzir cachaças de qualidade, Salinas foi ganhando destaque no cenário nacional cachaceiro (PEREIRA, 2021).

O município, além de fabricar as melhores e mais vendidas cachaças do Brasil, as quais são exportadas para diversos países, é o único a oferecer um curso superior em tecnologia e produção de cachaça, o qual capacita pessoas que querem investir nesse ramo. O curso de Tecnologia em Produção de Cachaça é ofertado pelo Instituto Federal do Norte de Minas Gerais, campus Salinas, presencialmente, e foi implantado no ano de 2005, por meio da Portaria MEC n 4.243, de 21 de dezembro de 2004. Anualmente, são ofertadas 30 vagas para o curso, cujo ingresso pode ocorrer mediante o Enem ou pelo vestibular tradicional. $\mathrm{O}$ objetivo do curso é formar tecnólogos que sejam capazes de atuar em todas as áreas da cadeia produtiva da cachaça de alambique, assegurando qualidade e produtividade com menor custo de produção (BRASIL, 2016).

Além do curso de produção de cachaça, Salinas possui o famoso Museu da Cachaça, inaugurado em dezembro de 2012. O espaço, composto por nove salas, apresenta, em cada uma delas, o histórico da cachaça na região e a importância do produto para a cultura e a economia local. Atualmente, o museu é um patrimônio da cidade de Salinas, por guardar não só informações sobre a produção histórica da cachaça na região, mas também por arquivar importantes elementos da cultura do município (PEREIRA, 2021). 


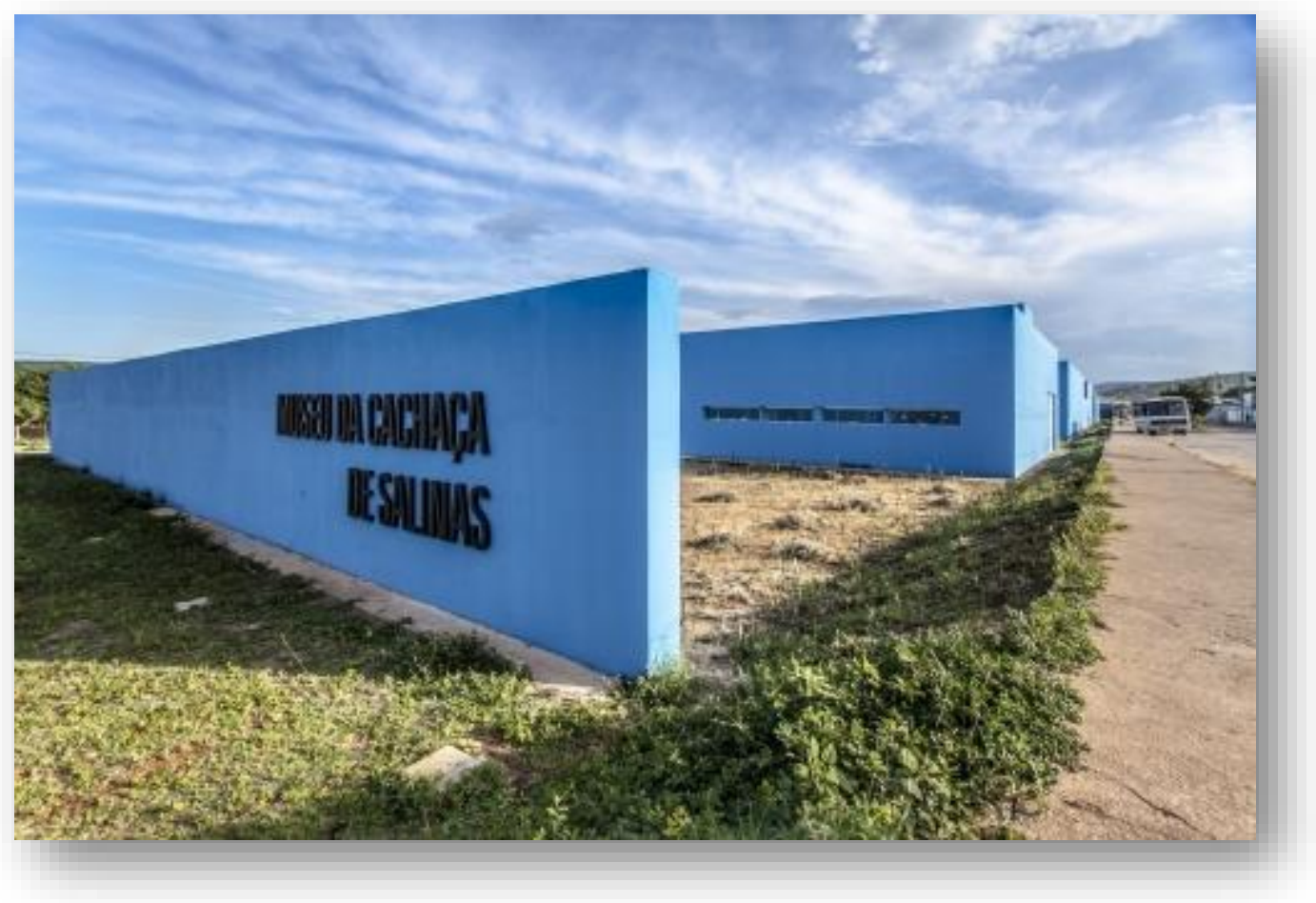

Foto 2 - Museu da Cachaça de Salinas Fonte: Prefeitura de Salinas

Outro elemento importante na cultura da cachaça na região de Salinas são as festas populares realizadas no município, com destaque para o festival da cachaça, realizado anualmente com apoio da prefeitura e dos produtores de cachaça. O objetivo do evento é dar visibilidade à bebida nacional e mundialmente, bem como alavancar o turismo da cidade. A festa atrai milhares de espectadores, tanto da cidade quanto de outras cidades circunvizinhas e do Brasil inteiro, com atrações para chamar atenção do público, como visitas a alambiques, shows, stands, degustação de cachaça etc. (PEREIRA, 2021).

Por tudo isso, a história da cidade se constrói fortemente marcada pela produção de cachaça, como uma atividade que fez crescer o local e rendeu emprego a muitos indivíduos. Atualmente, a cachaça é um produto de orgulho para os cidadãos de Salinas, pois faz com que, frequentemente, ela seja lembrada na mídia e pelo Brasil pela qualidade de suas bebidas, e o produto é responsável por movimentar a economia e o turismo da cidade e, mais ainda, é 
Onomástica Desde América Latina, n.4, v.2, julho - dezembro, 2021, p.130-146.ISSN 2675-2719 https://doi.org/10.48075/odal.v0i0.27524

um elemento importante na construção identitária e cultural dos moradores da região (PEREIRA, 2021).

Nos registros do MAPA (2020), Salinas é uma das cidades brasileiras que mais possui marcas de cachaça registradas, e cada uma dessas bebidas possui um nome que as designa. A produção dessas bebidas ocorre não somente na zona urbana da cidade, muitas delas são produzidas nas fazendas, povoados e distritos da zona rural do município, a exemplo das cachaças Caladinha, Puluzinha e Primadela. Tais nomes, que recebem uma forte influência da cultura regional, serão discutidos e analisados na seção a seguir.

\section{Nomes próprios de cachaça}

Os nomes que nos propomos analisar foram extraídos de entrevistas realizadas com moradores da cidade de Salinas no período de dezembro de 2019, coletadas para uma pesquisa de mestrado a qual visou o levantamento e a descrição do léxico salinense relacionado à cachaça.

Salinas sempre foi uma cidade conhecida pela expoente produção de cachaça, e esse legado foi marcado pelo produtor Anísio Santiago, dono de uma das marcas mais famosas do mundo: a cachaça Havana. Na década de 1960, quando essa marca começou a ultrapassar fronteiras estaduais e até internacionais, os demais produtores da bebida começaram a identificar seus produtos por meio de marcas, entre as quais surgiu a Puluzinha.

A cachaça Puluzinha é uma das mais antigas cachaças criadas na cidade. Seu idealizador, Policarpo Dias Correa, mais conhecido como Pulú, ganhou notoriedade pela produção artesanal de sua aguardente de cana. A fabricação ocorria na zona rural da cidade de Salinas e era responsável por empregar diversos moradores da região. Em um dos relatos obtidos na pesquisa, um salinense que trabalhou na produção da cachaça Puluzinha explica a origem do nome da bebida: 
Onomástica Desde América Latina, n.4, v.2, julho - dezembro, 2021, p.130-146.ISSN 2675-2719 https://doi.org/10.48075/odal.v0i0.27524

E o pessoal dele mora tudo ali. Mora tudo dentro da fazenda, aí. Mas o que acontece: a gente foi saindo, foi saindo. O povo foi saindo. Os mais velhos foram saindo. Os donos do lambico... Que nem o velho Pulu, ele acabou que não tava dando conta mais de mexer. Passou a fazer um alambique aqui no Buqueirão. Fizeram lá em Antônio Cardoso. Uma pinga boa danada também. Mas lá não dava conta. E a pinga do velho ali, Pulú, ficou com nome de Puluzinha. Chamava de Puluzinha, a pinga dele era Puluzinha. Chamava Puluzinha. O nome dele pôs na pinga. Agora essa pinga é de Antônio Cardoso. A pinga lá não sobrava para você vender (ENTREVISTADO 1).

De acordo com Franco (2020), um mesmo nome pode transitar entre diversas funções, como o fato de ser comum, próprio ou diferir aquilo que é nomeado, transformação que ocorre de acordo com parâmetros de tempo e espaço, bem como no sistema cultural de cada língua. Tal trânsito pode ser observado no nome Puluzinha, cujo antropônimo Pulu, que nomeia uma pessoa, transforma-se em oniônimo, cuja nomeação ocorre em uma marca.

Em cidades pequenas, é muito comum a adoção de alcunhas para designar pessoas, como é o caso do "velho Pulú", como era conhecido pelos moradores da região de Salinas. No caso da cachaça Puluzinha, pode ser observada a transformação de um apelido em nome de marca. Acreditamos que a escolha do nome deu-se devido ao prestígio social que o senhor Pulú tinha na cidade. O nome, que remete a uma pessoa de influência na região, dá ao produto nomeado a mesma influência do seu idealizador, de modo que a bebida, mesmo que em fase inicial, consiga se destacar no mercado.

Isso pode ser observado em muitos produtos comercializados na atualidade, que recebem o nome de influenciadores sociais amplamente conhecidos e que, por esse motivo, fazem com que o produto se destaque, inicialmente, não por sua qualidade, mas pela influência de quem o representa. É o caso de perfumes e bolsas, por exemplo, que recebem nomes de artistas (como Perfume Celso Portiolli e Bolsa Ana Hickmann).

Além disso, no caso da cachaça Puluzinha, pode ser observado, no nome, o uso do diminutivo, que também apresenta valor conotativo de valor afetivo. Ao discutir os valores semânticos do diminutivo, o gramático Bechara (2009) salienta que: 
Onomástica Desde América Latina, n.4, v.2, julho - dezembro, 2021, p.130-146.ISSN 2675-2719

https://doi.org/10.48075/odal.v0i0.27524

Fora da ideia de tamanho, as formas aumentativas e diminutivas podem traduzir o nosso desprezo, a nossa crítica, o nosso pouco caso para certos objetos e pessoas, sempre em função da significação lexical da base, auxiliados por uma entoação especial (eufórica, crítica, admirativa, lamentativa etc.) e os entornos que envolvem falante e ouvinte: poetastro, politicalho, livreco, padreco, coisinha, issozinho. Dizemos então que os substantivos estão em sentido pejorativo. À ideia de pequenez se associa facilmente à de carinho que transparece nas formas diminutivas das seguintes bases léxicas: paizinho, mãezinha, queridinha (BECHARA, 2009: 141).

Em Puluzinha, parece haver uma relação de afetividade ao nome, ao mesmo tempo em que há uma conotação de que a bebida é uma filha do "velho Pulú". Além do mais, o nome, ainda que talvez não tenha sido minuciosamente planejado, atende às observações feitas por Neumeier (2008), discutidas na seção anterior, visto que se distingue dos demais, é foneticamente agradável e possui grafia e pronúncia fáceis.

Outra cachaça, que surgiu mais recentemente em Salinas, é a Primadela, cuja nomeação ocorreu a partir de uma anedota, conforme explica seu próprio criador.

\begin{abstract}
- É. Engraçado porque eu comecei a mexer com essa cachaça que eu mexo hoje... E um cara foi tomar ela... Duas pessoas tomaram, e aí no hotel falou assim: "Essa cachaça... eu já tomei essa cachaça." Eu não poderia falar com ele que eu nunca tinha bebido dela, né? Aí o outro falou assim: "Ela tem gosto de Havana". Aí eu fui e falei: "Não é a Havana, mas é prima dela." ((risos)) Certo? Então essa cachaça que eu mexo hoje, ela tem o nome de "Primadela", porém não está registrada, está com um processozinho aí que mais para frente vai aparecer registrada aí, entendeu? É uma cachaça que tem uma procedência muito boa. Tá sendo muito bem manipulada. Tem um segredinho também... Acho que todo agricultor que produz a cachaça ele tem aquele segredo dele. Eu colhi muitas informações para eu poder mexer... Entendeu? E graças a Deus hoje a gente vê muita gente tomando dela $e$ elogiando. Né Zé? Você é testemunha disso. Então esse nome "Primadela" surgiu... Foi nesse dia aí (ENTREVISTADO 2)
\end{abstract}

A cachaça Havana é considerada a pioneira das cachaças na região de Salinas, e ainda hoje é um produto em que muitos produtores se inspiram, motivo pelo qual, em 2006, foi considerada patrimônio cultural imaterial para o município.

Reconhecendo a cachaça como importante atividade econômica e cultural, o prefeito de Salinas, José Antônio Prates, por meio do Decreto Municipal nº 3.728/2006, reconheceu a marca Havana, ícone das marcas produzidas no município, como Patrimônio Cultural Imaterial de Salinas, em face de sua história qualidade e notoriedade no mercado brasileiro e no exterior. Por meio do decreto, fato inédito no Brasil, o poder executivo municipal reconheceu o feito espetacular do produtor Anísio Santiago, empresário rural que conseguiu dar credibilidade e alto conceito de 
Onomástica Desde América Latina, n.4, v.2, julho - dezembro, 2021, p.130-146.ISSN 2675-2719 https://doi.org/10.48075/odal.v0i0.27524

qualidade, em todo o território nacional e no exterior, da mais importante e genuína bebida brasileira: a cachaça (BRAZ, 2007: 200).

No caso da cachaça Primadela, o nome, que surgiu a partir de uma anedota, foi inspirado na cachaça Havana, devido às suas características sensoriais serem semelhantes. Além disso, o fato de o nome da bebida fazer menção a um produto de renome no mercado é mais uma motivação para a sua escolha, visto que, conforme discutem Giacomini Filho e Borba (2010),

assim como as pessoas e os objetos, os produtos e empresas precisam ostentar nomes que os representem no contexto social e de mercado. A correta atribuição de um nome de marca pode significar êxito ou fracasso nos intentos de marketing, além das implicações legais e de responsabilidade social organizacional no uso e registro da marca (GIACOMINI FILHO e BORBA, 2010: 218).

Outrossim, na grafia do nome, é possível observar um outro fenômeno comum na criação de nomes comerciais, conforme discutido por Guérios, que é a criação de um nome por meio do processo de composição, em que as palavras que formam o nome denotam as características do produto. No caso da cachaça Primadela, a junção do substantivo prima e do pronome possessivo dela indica a relação conotativa de parentesco que a bebida possui com a cachaça Havana.

Outra cachaça feita de modo artesanal, na zona rural da cidade de Salinas, que apareceu nos relatos dos entrevistados, foi a Caladinha.

- E essa pinga que vocês produziam, vocês colocaram algum nome nela?

- Pai colocou o nome de Caladinha. Naquela época a gente tinha medo da Justiça.

- ((risos))

- Porque lambicava por debaixo dos panos, né?

- Aí a pessoa: "Como é que chama a pinga sua?". "Caladinha" ((risos)) (ENTREVISTADO 3)

No nome da cachaça em questão, é possível observar a escolha do oniônimo em virtude das circunstâncias do nascimento do produto. Devido à burocracia no processo legal de registros de cachaça, durante muito tempo, alguns produtores deixavam de registrar a 
Onomástica Desde América Latina, n.4, v.2, julho - dezembro, 2021, p.130-146.ISSN 2675-2719 https://doi.org/10.48075/odal.v0i0.27524

bebida e vendiam-na informalmente. A escolha do nome Caladinha, contada de modo muito humorado pelo entrevistado, justifica o modo como ela era produzida e vendida na zona rural de Salinas.

Apesar de não ser recomendado pelo MAPA, é muito comum a comercialização da pinga nas garrafas pets, prática muito recorrente na cidade de Salinas e em outros locais em que se produz cachaça. No caso da Caladinha, cuja venda ocorria desse modo, em garrafas pets, o entrevistado conta que era comercializada aos vizinhos, botequeiros ou pessoas que trabalhavam em sua fazenda e, às vezes, queriam receber o pagamento em pinga, a qual, segundo o relato, era de extrema qualidade - mas tudo era feito, conforme descrito pelo informante, "debaixo dos panos".

Isso demonstra que o processo de nomeação das cachaças está intimamente relacionado às práticas culturais de cada indivíduo nomeador, que conferem sua identidade à bebida por ele produzida.

\section{Considerações finais}

Neste texto, foi possível observar a proximidade entre as áreas da Lexicologia e da Onomástica, de modo que, assim como o léxico, a escolha de nomes próprios evidencia fatores culturais e sociais inseridos nesses nomes. A análise dos três oniônimos que designam as cachaças salinenses - Puluzinha, Caladinha e Primadela - evidenciam que, em seus processos de formação, é possível observar não somente questões estruturais da língua, mas também empreender discussões com base em nomes que demonstram a criatividade e a identidade do nomeador.

Com isso, nota-se que os estudos acerca dos nomes próprios podem fornecer dados relevantes sobre o léxico, a língua e, no caso da cachaça, sobre a cultura da região de Salinas, marcada, inclusive no que se refere à cachaça, por costumes e tradições populares. Isso mostra o quão importante é o desenvolvimento e a expansão das pesquisas nessa área. 


\section{REFERÊNCIAS}

Amaral, Eduardo Tadeu Roque; Seide, Márcia Sipavicius. (2020) Nomes próprios de pessoa: introdução à antroponímia brasileira. São Paulo: Blucher. Disponivel em: https://openaccess.blucher.com.br/download-pdf/453

Barbosa, Maria Aparecida. (1990) Lexicologia, lexicografia, terminologia, terminografia, identidade científica, objeto, métodos, campos de atuação. In Anais do II Simpósio LatinoAmericano de Terminologia. I Encontro Brasileiro de Terminologia Técnico-Científica. Brasília, 1990. p. 152-158.

Bechara, Evanildo. (2009) Moderna gramática portuguesa. 37. ed., Rio de Janeiro: Nova Fronteira.

Biderman, Maria Tereza Camargo. (1978) Teoria lingüística: lingüística quantitativa e computacional. Rio de Janeiro: Livros técnicos e Científicos.

Brasil. Lei $\mathrm{n}^{\mathrm{o}}$ 13.773, de 19 de dezembro de 2018. Confere ao Município de Salinas, no Estado de Minas Gerais, o título de Capital Nacional da Cachaça. Disponível em: http://www.planalto.gov.br/ccivil_03/_ato2015-2018/2018/lei/L13773.htm. Acesso em: 15 mai. 2021.

Brasil. Tecnologia em Produção de Cachaça - IFNMG Salinas. (2016). Disponível em: https://www.ifnmg.edu.br/cursosmenu/338-portal/salinas/salinas-cursos-

superiores/tecnologia-em-producao-de-cachaca/13591-tecnologia-em-producao-de-cachaca.

Acesso em: 15 mai. 2021.

Coelho, Braz José. (2008) Dicionários - estrutura e tipologia. In: Linguagem: Lexicologia e Ensino de Português. Catalão: Modelo, 2008: 13-43.

Couto, Hildo Honório do. (2007) Ecolinguística: estudo das relações entre língua e meio ambiente. Brasília: Thesaurus Editora.

Franco, Yolanda G. López. (2020) Las relaciones intercategoriales e intracategoriales en antroponimia. El caso de los nombres de pila en francés de Francia y en español de México. In: Onomástica Desde América Latina, n.1, v.1, 2020, 222 -247. https://doi.org/10.48075/odal.v1i1.24169.

Giacomini Filho, G.; Borba, O. R. (2010) Nomes de Marca: aspectos mercadológicos e onomásticos. In: Revista Eletrônica Signos do Consumo. Vol. 2. no. 2. São Paulo: Universidade de São Paulo, 2010, 217-229.

Guérios, R. F. Mansur. Onionímia ou Onomástica Industrial. (1973). In.: BARBADINHO NETO, R. (Org.). Estudos em homenagem a Cândido Jucá (Filho). Rio de Janeiro: Simões. 
Isquerdo, Aparecida Negri. (2001) "Vocabulário do seringueiro: campo léxico da seringa.”. In: Isquerdo, Aparecida Negri; Pires, Ana Maria P. de Oliveira.(Orgs). As ciências do léxico: lexicologia, lexicografia e terminologia, v.1. Campo Grande: Ed. UFMS.

Mapa - Ministério da Agricultura, Pecuária e Abastecimento. (2020) A cachaça no Brasil: Dados de Registro de Cachaças e Aguardentes. Brasília: MAPA/AECS.

Neumeier, M. The Brand Gab. (2008) O abismo da marca. Porto Alegre: Bookman.

Neves, Norma Lúcio Horta Neves. (1971) Nomes próprios comerciais e industriais no português. $1^{\text {a }}$ Edição.Belo Horizonte: Imprensa Oficial do Estado de MG.

Pereira, Mauricio Alves de Souza. (2021) O léxico da cachaça em Salinas-MG. Dissertação (mestrado) - Universidade Federal de Minas Gerais, Belo Horizonte. Disponível em: https://repositorio.ufmg.br/handle/1843/35419

Sapir, Edward. (1969) Língua e ambiente. In: Linguística como ciência. Rio de Janeiro: Acadêmica, 1969, 43-62.

Seabra, M. C. T. C. (2006) Referência e Onomástica. In: Magalhães, J. S. de; Travaglia, L. C. (Orgs.). Múltiplas perspectivas em linguística: Anais do XI Simpósio Nacional e I Simpósio Internacional de Letras e Linguística (XI SILEL). Uberlândia: ILEEL, 2006, 1953-1960. 